\title{
"NO VENGO A PEDIRTE NADA": LA MÚSICA EN Villa Rica, Cauca, como un espacio donde se hace sociedad
}

\author{
Manuel Sevilla \\ PhD Antropología, Universidad de Toronto \\ Profesor Asistente Departamento de Comunicación y \\ Lenguaje Pontificia Universidad Javeriana \\ msevilla@javerianacali.edu.co
}

\begin{abstract}
Resumen
[STE ARTí́CULO PRESENTA RESULTADOS DE UNA INVESTIGACIÓN RECIENTE SOBRE LAS PRÁCTICAS -musicales tradicionales en el municipio caucano de Villa Rica, Cauca, Colombia. Se describen tres contextos sociales (celebración de la natividad del Niño Dios, velorios de niños y adultos y espacios de trabajo y esparcimiento) y se exploran las distintas maneras como se atienden las exigencias de recursos físicos y de trabajo humano allí presentadas. A partir de esto, se argumenta que las prácticas musicales tradicionales son una instancia privilegiada donde las personas comunican, transforman y reafirman distintos parámetros de acción colectiva y que en Villa Rica se sustenta en prácticas solidarias. El argumento central va en concordancia con la idea de que las músicas tradicionales son un espacio donde se hace sociedad y no sólo un reflejo de ella.

PALABRAS ClavE: música tradicional, bundes, adoraciones, antropología de la música, Villa Rica, Cauca
\end{abstract}

\section{"No Vengo a Pedirte nada": Villa Rica Music as a Space where Society is Made (Cauca, Colombia).}

\begin{abstract}
THIS PAPER PRESENTS THE RESULTS FROM A RECENT RESEARCH ABOUT TRADITIONAL MUSIC PRACTICES AT Villa Rica, Cauca, Colombia. From an ethnographic description of three social contexts (the Nativity celebration, children and adults wake, and work and leisure spaces), and a exploration of different ways to deal with demands of physical and human work resources, the article argues that traditional music practices are privileged instances where people communicate, transform and reassert the different criteria of collective action. Criteria that are at the basis of solidarity practices of Villa Rica villagers. In this sense, the main argument agrees with the idea that traditional music practices are spaces where society is made, and not just a reflection of it.

KEY Words: Traditional Music, bundes, worship, anthropology of music, Villa Rica, Cauca
\end{abstract}

\section{Revista Colombiana de Antropología}

Volumen 45 (2), julio-diciembre 2009, pp. 399-429 
 MUNicipio CAUCANO DE VILLA RICA, AL SUR DEL VALLE GEOGRÁFICO DEL río Cauca, Colombia, es un cruce de caminos en la mitad de un inmenso cañaduzal. Por décadas sus habitantes han combinado faenas cotidianas y encuentros ocasionales con cantos que hoy en día son la base de una tradición viva. En el centro de este universo musical están las mujeres mayores, abuelas que ayer cosechaban cacao y hoy educan a los niños entre historias y cantos que datan de tiempos idos. A su lado, tamboreros y músicos de viento complementan un sonido que es característico de esta zona del país.

La manifestaciones lírico-musicales y dancísticas más conocidas de la región son las Adoraciones del Niño Dios, que fueron abordadas en profundidad por estudios musicológicos (Portes de Roux, H., 1986a y I986b) y antropológicos (Atencio, J. y Castellanos, I., I982) en los años 80 y por sucesivos trabajos de menor extensión en años más recientes (Angulo, M. E., 2005; Aristizábal, M., 2005). Quedan, sin embargo, numerosos aspectos inexplorados de estas fiestas de la natividad y existe, además, una gran variedad de cantos tradicionales asociados a otros contextos sociales que no han recibido igual atención por parte de la academia. Una primera categoría de estos cantos, mencionada de forma tangencial en algunos estudios, y aun vigente, comprende los bundes y salves que acompañan los velorios de niños y adultos. Una segunda categoría es la de los cantos asociados a contextos de esparcimiento y trabajo conocidos como los bailes de socio, las quemas y las jornadas de cosecha de cacao. Estos desaparecieron de la zona y son los menos documentados en la literatura especializada.

Aquí se sintetizan algunos de los resultados de un estudio reciente $^{1}$ (2007-2008) que recopiló una serie de cantos tradicionales en Villa Rica y analizó diferentes aspectos de la organización social de los contextos de ejecución musical relacionados (celebraciones religiosas, velorios

I. Estudio derivado de la investigación Veinte años de adoraciones: Producción cultural y fiestas del Niño Dios en el norte del Cauca (I986-2007), llevada a cabo por investigadores de la Pontificia Universidad Javeriana Cali y la Universidad del Valle entre diciembre de 2007 y diciembre de 2008, con el apoyo de la Fundación para la Promoción de la Investigación y la Tecnología del Banco de la República de Colombia. de niños y adultos y espacios de esparcimiento). En términos de la discusión sobre música y organización social, se argumenta que las prácticas musicales tradicionales son una instancia importante para la comunicación, 
transformación y reafirmación de parámetros sociales en Villa Rica, gracias a una serie de prácticas solidarias en torno a la música. Se argumenta también que la mayoría de estos procesos han ocurrido y ocurren de acuerdo con lo que denominamos dinámica colateral y que en ellos juegan un papel preponderante personas provenientes de la comunidad (agentes internos), en su mayoría mujeres mayores.

El texto está organizado de la siguiente manera: al inicio se exponen los aspectos conceptuales y la forma como se desarrolló el estudio y una breve discusión sobre Villa Rica y el norte del Cauca en términos socioeconómicos. La sección principal presenta los tres tipos de contextos sociales donde se dan las prácticas musicales tradicionales y las diferentes maneras como se sustentan las exigencias que impone su realización. Al final se hace un análisis en torno a la idea de que las músicas tradicionales son una instancia donde se hace sociedad, más que un mero reflejo de la sociedad. ${ }^{2}$

\begin{abstract}
2. El autor agradece a sus compañeros de investigación, los musicólogos Heliana Portes de Roux y Alejandro Martínez Carvajal de la Universidad del Valle, sin cuyos valiosos aportes no se habría podido realizar este artículo, así como los comentarios de Elías Sevilla Casas. También agradece la colaboración generosa del grupo de cantoras, instrumentistas, gestores culturales y comunidad en general del municipio de Villa Rica, Cauca. El estudio se adelantó con fondos aportados por el Banco de la República y la Pontificia Universidad Javeriana Cali. Contó además con el apoyo de la Corporación Cultura Viva y el equipo Martina Pombo para la elaboración del material sonoro, fotográfico y video.
\end{abstract}

\section{Aspectos Conceptuales}

l artículo parte DE DOS PRESUPUESTOS. PRIMERo, QUE LAS MÚSICAS

- tradicionales pueden definirse a partir de su relación con el ámbito económico y de sus formas de transmisión entre los miembros de un grupo social. Segundo, que son instancias sociales donde se ponen en común y se discuten valores colectivos de gran importancia para la comunidad.

\section{La idea de música tradicional}

L TÉRMINO MÚSICA TRADICIONAL ES POLÉMICO Y HA DADO PIE A INNUMERA-bles discusiones que siguen vigentes, tanto a nivel académico -como de políticas públicas y de movimientos identitarios, 
donde la práctica musical ha cobrado gran importancia como símbolo de unidad cultural (Sevilla, M., 2008). Dentro de las distintas perspectivas que ofrece la literatura especializada, nos enfocaremos en la que exponen G. Booth y T. Kuhn (I990) en un extenso artículo que propone una definición de las categorías de música tradicional, académica y popular (Folk, Art, y Pop music). G. Booth y T. Kuhn utilizan como criterios esenciales de diferenciación los factores económicos y de transmisión asociados a cada categoría de práctica musical. En el caso de la música tradicional, plantean que esta no tiene una asociación directa con la obtención de réditos, en contraste, por ejemplo, con la popular difundida a través de medios masivos de comunicación, que tiene claros intereses en los ingresos que generan las distintas formas de consumo por parte de sus audiencias. En lo que a transmisión y apropiación respecta, en el caso de la música tradicional estos procesos se dan por medio de la participación sistemática en diferentes actividades sociales donde la acción musical ocurre no necesariamente a través de

3. De hecho, la claridad de los criterios de categorización y, a su vez, el reconocimiento de la flexibilidad de los linderos de esta perspectiva permiten superar los inconvenientes de otras definiciones que parten de dicotomías bastante cuestionables. Está, por ejemplo, la recurrente oposición entre músicas tradicionales y "contemporáneas" o "modernas", que hace alusión a lo que se interpretaba "antes" y lo que se interpreta hoy, o aquella entre músicas tradicionales y urbanas, que resalta la ubicación geográfica como rasgo esencial (donde las músicas tradicionales serían las que surgen o se interpretan en el entorno rural). Estas dicotomías son problemáticas porque, por una parte, desconocen la permanente transformación de las prácticas musicales (muchas músicas tradicionales siguen interpretándose hoy) y, por otra, olvidan la relatividad de los linderos en la práctica musical (hay músicos tradicionales radicados en las ciudades y muchos de ellos alternan con interpretación de música popular. Más aun, como ocurría con los cantos de quemas y bailes de socio en Villa Rica, los repertorios populares pueden nutrir los repertorios tradicionales). procesos pedagógicos exclusivos, a diferencia, por ejemplo, de la dedicación específica al aprendizaje musical que supone la música académica. Los autores consideran, sin embargo, que estas definiciones son apenas categorías para el análisis y que en la práctica los límites entre una y otra se diluyen, algo que pudimos observar en Villa Rica, en el caso de la música de quemas, bailes de socio y cantos de laboreo. Por la claridad de los criterios y el reconocimiento de la flexibilidad de los linderos, la definición de G. Booth y T. Kuhn fue el punto de partida para el estudio. $^{3}$ 


\section{Prácticas musicales como instancia social}

NTIENDO POR PRÁCTICAS MUSICALES TRADICIONALES UNA INSTANCIA COM-
pleja donde se entretejen distintos aspectos de la vida de una
Comunidad: los que hacen la música, los que la escuchan, los
elementos musicales que son transformados y se conjugan para la creación y la interpretación y los procesos de transmisión del conocimiento musical, etcétera. ${ }^{4}$ A esta red de relaciones alude la 4. Como se discute en el análisis, en Villa Rica esta tajante división entre intérpretes y audiencia se relativiza. socióloga estadounidense J. R. Blau cuando afirma que "la música es una circunstancia social":

La música es la expresión de experiencias comunitarias compartidas y de vínculos de cohesión social, en tanto que [...] los eventos musicales involucran a muchas personas, las integran en grupos y promueven la cooperación a través de reglas y convenciones. Los vínculos sociales son alimentados con canciones de cuna, himnos nacionales, cantos de protesta, marchas militares y spirituals. Baudelaire, al tratar de explicar el gusto universal por la música y su efectividad para integrar grandes cantidades de extraños, afirmó que "la música inspira ideas similares en mentes distintas" (Blau, J. R, I988, p. 884).

En general, la antropología reconoce las prácticas de creación artística e intelectual como espacios claves para la generación y transformación de la cultura, entendida esta última en el sentido propuesto por C. Geertz (2000): "Una red de significados en la que estamos inmersos los miembros de una comunidad". Al respecto, M. Mahon (2000, p. 469) señala que un tema de recurrente reflexión en la disciplina ha sido "las formas como las personas utilizan los productos culturales para construir, articular y diseminar ideologías acerca de [la vida social] ... y su impacto sobre las relaciones sociales, las formaciones sociales y los significados sociales". Vemos entonces que las prácticas de producción cultural, en este caso las prácticas musicales y sus productos asociados, son escenarios privilegiados para la elaboración de sentidos y significados colectivos, donde las comunidades se definen, discuten y reformulan a sí mismas. Ahora bien, estos procesos de autorrepresentación no son necesariamente armónicos, y en muchos casos los hábitos culturales se convierten en candentes espacios de interpelación y lucha simbólica, donde "las 
"No vengo a pedirte nada": la música en Villa Rica, Cauca...

hegemonías son relativizadas” y eventualmente transformadas (Kondo, K. D., I997, p. 4).

Una revisión de la literatura sobre el tema permite identificar dos tipos de dinámicas sociales en las que las prácticas musicales se asocian con procesos de discusión, transformación y reafirmación de parámetros simbólicos de acción colectiva dentro de una comunidad. Están por un lado aquellas dinámicas donde estos procesos ocurren de forma colateral respecto a otros hechos sociales; es decir, no se derivan, o por lo menos no en forma evidente, de una iniciativa ideológica o estética que se proponga forjar, reafirmar o subvertir ciertas concepciones. Son más bien resultado de la participación y vinculación de las personas a ciertas actividades sociales donde está presente la música, pero sin que esta sea el epicentro (e.g. fiestas religiosas, velorios y jornadas laborales). En el caso del suroccidente colombiano, algunos ejemplos pueden observarse en los conjuntos de flautas traversas que acompañan el küc'h wala o la fiesta "del niño" entre los indígenas nasa del suroccidente andino colombiano (Miñana, C., 2008), los conjuntos de chirimía que acompañan las ceremonias de posesión de gobernador del cabildo entre los indígenas yanaconas de Popayán (Sevilla, M., 2006) y los cantos de Adoración del Niño Dios entre comunidades rurales negras del norte del Cauca (Portes de Roux, H., 1986a). Existen, por supuesto, múltiples ejemplos similares en el mundo (Pitts, W., I99I).

En todos estos casos, el hecho musical ocurre en torno a una actividad social más amplia (en el sentido de que la incluye), pero al mismo tiempo se constituye en un escenario donde se reafirman concepciones sociales y se educa a los menores en costumbres arraigadas (los niños nasa que participan en las alumbranzas), se reivindica la autoridad de los mayores (las abuelas que conocen las salves y las loas a la Virgen en el norte del Cauca) o, incluso, se introducen cambios a una tradición que, con el tiempo, se vuelven referentes de autenticidad (como se aprecia en los repertorios remozados de los flautistas yanaconas en Popayán).

En contraste con lo anterior, existe una segunda dinámica en la que se observa un uso instrumentalista de formas expresivas musicales para fortalecer o cuestionar ciertos presupuestos sociales preexistentes y, en no pocos casos, para criticar y tratar de subvertir el orden predominante. Aquí los procesos de reafir- 
mación y transformación de parámetros sociales asociados a la música dejan de darse de forma colateral, como en la primera dinámica, y pasan a ser un elemento fundamental, cuando no el más importante, de transmisión e instancia de escenificación de mensajes que, por lo general, responden a agendas políticas y estéticas:

Los productores culturales emplean, de forma consciente, recursos artísticos —música, cine, video, artes visuales- para satisfacer los propósitos de la expresión creativa y también para [...] atacar estereotipos y prejuicios, y para construir, reconfigurar y comunicar mensajes relacionados con identidades raciales, étnicas, de género, sexuales y nacionales (Ginsburg, F., I99I, p. 96).

Esta innegable dimensión política que cobran las prácticas musicales al formar parte de procesos más amplios de activismo ha motivado numerosos estudios desde la antropología y la sociología (Conklin, B. A., I997; Blau, J. R., I998; Rasmussen, L., I995; Hesmondhalgh, D.y Pratt, A. C., 2005; Sevilla, M., 2008), que tipifican las distintas formas de debates simbólicos que allí se dan. Por último, existen diferencias entre los agentes que toman parte en ambas dinámicas de discusión, transformación y reafirmación simbólica (colaterales e instrumentales), sobre todo en lo relacionado con el origen interno o externo de los productores culturales involucrados (si pertenecen o no a la comunidad de referencia). ${ }^{5}$

Argumento, en este texto, primero, que las prácticas musicales tradicionales en Villa Rica son una importante instancia para la comunicación, transfor5. El papel que los investigadores jugamos en este panorama, bien sea como agentes internos o externos, amerita una mirada a fondo, como lo sugiere K. Kaufman Shelemay, estudiosa de la música en comunidades de la diáspora etíope: "Es necesario reflexionar acerca del rol del investigador que, en su esfuerzo por documentar los procesos de transmisión de las músicas tradicionales, termina volviéndose parte de los mismos procesos" (2008, p.I4I).

mación y reafirmación de parámetros sociales y que esto se sustenta en arraigadas prácticas solidarias. Segundo, que la mayoría de estos procesos ocurren en la actualidad de acuerdo con lo que hemos denominado dinámica colateral. Tercero, que la mayoría de agentes participantes son de tipo interno, aunque desde los años 80 ha habido significativos casos de articulación con agentes externos. 
"No vengo a pedirte nada": la música en Villa Rica, Cauca...

\section{Desarrollo Del estudio}

A INICIATIVA DE ADELANTAR UNA INVESTIGACIÓN SOBRE LA MÚSICA TRADI-
cional en el municipio caucano de Villa Rica surgió en mayo
de 2007 a partir de una revisión bibliográfica sobre músicas tradicionales de la zona del norte del Cauca, donde se relacionaron los pocos trabajos existentes acerca de la música de comunidades afrodescendientes en los valles interandinos de los ríos Patía y Cauca (Sevilla, M., et. al., 2008). El texto inédito de H. Portes de Roux (I986a) y su acetato con una veintena de cantos (I986b) y el de J. Atencio e I. Castellanos (I982) en zonas aledañas a Villa Rica se incluyeron dentro del listado y fueron valorados como un paso significativo hacia la documentación de la producción musical en una zona que ha recibido poca atención en este sentido. Visitamos el municipio y propusimos a los músicos de la Fundación Villa Rica un trabajo conjunto donde se documentaran los cantos existentes (aprovechando las actuales posibilidades tecnológicas de grabación en terreno) y se abordaran aspectos antropológicos que los estudios anteriores no habían tocado o apenas esbozaron. La iniciativa tuvo buena acogida y el trabajo se realizó entre los meses de diciembre de 2007 y diciembre de 2008. El informe final, del que se deriva este artículo, se realizó entre enero y septiembre de 2009.

El estudio asumió un enfoque cualitativo y empleó un diseño etnográfico y documental. Se hicieron 20 entrevistas semiestructuradas entre diferentes actores sociales vinculados de forma directa o indirecta con la actividad musical tradicional en Villa Rica y con expertos de la zona. Se llevaron a cabo cinco grupos focales y dos jornadas colectivas de grabación de cantos en la casa comunal "El Palenque" de Villa Rica. En distintos momentos, a lo largo de diez meses, se observó y participó en diferentes celebraciones, ensayos de grupos musicales y reuniones sociales. También se adelantó una extensa revisión bibliográfica para precisar referentes conceptuales, elaborar guías de observación y entrevistas, así como una revisión de material documental escrito y sonoro sobre la zona del norte del Cauca, disponible en fuentes dentro y fuera de Cali (Universidad del Valle, Instituto Popular de Cultura, Universidad del Cauca, distintas ONG con trabajo acreditado en la región y archivos particulares de investigadores). 


\section{Villa Rica y el norte del Cauca}

A ZONA PLANA DEL NORTE DEL CAUCA ES UN VALLE DE CERCA DE 80 MIL hectáreas que se extiende entre las cordilleras occidental y central, Len el límite entre los departamentos de Valle del Cauca y Cauca. Desde un punto de vista administrativo, la región está dividida en los municipios caucanos de Villa Rica, Miranda, Corinto, Caloto, Santander de Quilichao, Padilla, Puerto Tejada, Suárez, Buenos Aires y el recién constituido Guachené. Sin embargo, desde una perspectiva cultural es posible encontrar grandes similitudes con las poblaciones vallecaucanas de Quinamayó, Timba, Guachinte y Robles (De Roux, G. y Yunda, A. C., 200I; Aprile, J., I994). Todas estas comunidades mantienen un permanente contacto con Cali, considerado el polo metropolitano más importante de la zona.

Durante la Colonia, las haciendas del norte del Cauca incorporaron la fuerza de trabajo por vía forzada y en forma de mercancía (esclavos africanos), en contraste con las haciendas andinas que lo hicieron, al menos parcialmente, a través de arreglos semiserviles y rentísticos con la población indígena circundante (Díaz de Zuluaga, Z., I983, p. IO2). Esto condujo a que, en el marco de la economía neogranadina y la republicana temprana, la riqueza de un hacendado del Gran Cauca se midiera por el número de esclavos, cuyo valor podía llegar a ser muy superior al de la tierra, las construcciones u otros elementos de producción (Jaramillo Uribe, J., 200I, p. I4).

Opuesto a lo que ocurrió en zonas del Caribe y Estados Unidos, las haciendas nortecaucanas no desarrollaron una economía de plantación debido, entre otras razones, a que la suya era una función de apoyo a otras actividades más lucrativas (la concentración de esclavos y la explotación minera). En consecuencia, muchos de los bosques tropicales y zonas pantanosas ubicadas dentro de las extensas propiedades permanecieron sin intervenir y se convirtieron décadas después en refugio de cimarrones y esclavos libertos (Bermúdez, A., I997, p. 69; Díaz de Zuluaga, Z., I983, p. IOI-IO2). Bajo las nuevas condiciones republicanas, las comunidades allí asentadas fueron la base de los núcleos campesinos negros contemporáneos. ${ }^{6}$ Estas

6. F. Urrea y T. Hurtado (I997, p. 199) dan cuenta de otro importante flujo de población negra al norte del Cauca, mucho más reciente y proveniente del pacífico caucano y nariñense, el Chocó y Buenaventura. Los inmigrantes llegaron a finales de los años 60 y 70 atraídos por las posibilidades de trabajo en los complejos agroindustriales cañeros. 
circunstancias contribuyeron a configurar la particular relación de interdependencia entre poblaciones negras de diferentes tamaños (desde cascos urbanos como Puerto Tejada y Villa Rica hasta las veredas de estos municipios) y los actuales ingenios

7. Para una mirada detallada a las etapas de formación de las comunidades campesinas negras en la región ver G. de Roux y A. C. Yunda (200I); J. Arocha (I995), G. Colmenares (I983) y M. Caicedo (2003). azucareros, que se consolidaron como complejos agroindustriales a partir de la década del 60 (Urrea F, y Hurtado, T., 1997). ${ }^{7}$

En el caso puntual de Villa Rica, este panorama socioeconómico, donde confluyen elementos de una arraigada tradición campesina y propios de la vida urbana, se vio afectado por la Ley 2I8 de I995 (conocida como "Ley Páez"), que brindaba atractivos estímulos para el establecimiento de empresas en el Cauca como medida de apoyo para la reconstrucción del departamento luego de la avalancha del río Páez en la zona montañosa del suroriente (estribaciones de la cordillera central). En I999 Villa Rica ascendió a la categoría de municipio y es en la actualidad un punto importante de tránsito a raíz de su cercanía a las empresas del parque industrial del norte del Cauca. No obstante, esto no ha significado gran prosperidad económica: el poblado rural donde se realizó el estudio de Portes de Roux (I986a) dos décadas atrás es ahora un municipio de I4 mil habitantes con altos niveles de desempleo y pobreza, a los que sus pobladores hacen frente combinando las iniciativas de negocio propias de un centro urbano (el rebusque materializado en pequeños negocios de víveres, abarrotes, venta de minutos a teléfono celular y transporte informal de pasajeros), con las actividades agrícolas en las pocas fincas familiares que se mantienen en la periferia. Muchas personas trabajan en los ingenios aledaños y en las empresas del parque industrial. Este es el panorama socioeconómico donde se daban y se dan las prácticas musicales que se describen a continuación.

\section{Contextos SOCIALES DE LA MÚSICA TRADICIONAL EN VILLA RicA}

STA SECCIÓN INTRODUCE TRES CONTEXTOS SOCIALES Y SUS CORRESPON- dientes prácticas musicales tradicionales, documentadas en Lilla Rica: las celebraciones religiosas en torno al Niño Dios (Adoraciones y Fiesta de Reyes), los velorios de niños y adultos 
(bundes y salves), y los espacios de reunión con amigos (quemas, bailes de socio y cantos de laboreo). ${ }^{8}$
8. Los lectores podrán encontrar abundante material fotográfico y en video sobre estas prácticas musicales en http://www.martinapombo.com. Están disponibles también grabaciones de los cantos que se mencionan en el artículo.

\section{"Vamos a adorar": loas y jugas en las fiestas de Adoraciones y Reyes}

\[ \begin{array}{l}\text { ASTA HACE UNOS QUINCE AÑOS EXISTIERON EN VILLA RICA DOS TIPOS DE } \\ \text { festividad asociada a la natividad: las Adoraciones del Niño } \\ \text { Dios y la Fiesta de Reyes. Mientras que la actividad en torno a }\end{array} \]
las primeras se mantiene, las segundas parecen haber desapareci-
do definitivamente. Al respecto dice una cantora de Villa Rica:

Las fiestas de Reyes se acabaron porque se murió Otoniel Balanta, el que las hacía cada año, pero regio. Él hacía unos Reyes en una carroza llevando algunas mujeres. iPero qué cosa tan divina! Entonces empezaron a decir que él se robaba la plata y se ofendió y no siguió haciendo las cosas. Se quedó quieto. Hace como diez años [1998] hicieron aquí unos mini-Reyes, pero no es como él los hacía. (LD, mujer, 72 años.)

Las Adoraciones del Niño Dios son celebraciones públicas que se desarrollan en torno a un pesebre comunal y en las que participan distintos sectores de la comunidad. Se llevan a cabo en los tres primeros meses del año e incluso en abril, pero en todo caso antes de la Semana Santa. Cada vereda del municipio organiza sus propias Adoraciones y procura que no se crucen con las de una localidad vecina para así poder asistir como cantora, músico o simple observador. La celebración comienza el viernes con una alborada y se extiende hasta el domingo:

Desde el viernes empiezan a quemar cohetes, la alborada empieza desde el viernes con la gente que se pone a orar y luego a quemar su cohetito. Yo me acuerdo tanto que la gente de otras partes iba y le vendían pedacitos para completar la plata y ellos vender fritanga o hacían unas barraquitas con guadua e iraca. (VP, mujer, 70 años.)

En términos de organización social, las Adoraciones involucran un complejo entramado de roles y actores que están al frente de dos grandes aspectos relacionados con etapas distintas de la celebración: 
a. El contenido y la escenificación de los diferentes productos culturales (en las semanas previas y durante los días de la Adoración).

b. La consecución de recursos que hagan posible su realización (por lo general, con varios meses de anticipación).

La participación en estos dos ámbitos no es excluyente y, de hecho, suele estar a cargo de las mismas personas. Aquí se describen los principales elementos relacionados con el aspecto a. La mirada detallada a la consecución de recursos, se hará más adelante.

Se dan tres tipos de manifestaciones lírico-musicales en las Adoraciones: las recitaciones de niños frente al pesebre (loas), los cantos de adoración (jugas de adoración) y las danzas que los acompañan (baile de juga), estos últimos con participación de miembros de todas las edades. Su articulación y ejecución está a cargo de un grupo de señoras mayores con alto prestigio entre la comunidad, conocidas como las "síndicas" de la Adoración. La fiesta tiene como eje principal una escenificación dramática que dura dos días y cuyo argumento central es el "robo" del Niño Dios (la desaparición de un muñeco guardado con especial esmero para la ocasión), su búsqueda de casa en casa (viernes), su hallazgo y la celebración de regocijo (sábado). La dramatización incluye procesiones por las calles del municipio y acompañamiento musical. De igual forma, se observan los siguientes roles, encarnados por jóvenes entre los siete y los dieciocho años: primera madrina, primer padrino, segunda madrina, segundo padrino, pastoras, samaritana, reina, princesa, indios, rey, ángel de las nubes, Virgen, San José, Reyes magos y soldados (Portes de Roux, H., I986a; Atencio, J. y Castellanos, I., I982). Cada uno tiene un vestuario específico y un parlamento asignado, este último trasmitido a los actores por sus abuelos, tíos y padres, muchos de los cuales tuvieron el mismo rol durante su infancia. A continuación se citan algunos de los parlamentos de la Virgen, San José y la Madrina luego de que el Niño ha sido recuperado (sábado) (elaborado entre Portes de Roux, H., I986a y estudio de 2008): 
Habla la Virgen:

Yo soy la Virgen la madre del Redentor hoy he venido a entregar al padrino y la madrina que lo vengan a cargar.

Abran campo pastoras que vamos al portal a adorar al Mesías que lo vamos a arrullar.

Adiós Niñito bonito adiós que hoy te vamos arrullar hasta el año venidero que te vengan a cargar.

Aplausos generales.

Palabras de San José:

San José tenía celos en el parto de María en el vientre de la Madre el Niño se sonreía.

Palabras de la primera madrina del niño:

Como madrina del Niño le he venido a saludar para mostrarle mi cariño me inclino ante su altar.

Y que canten las pastoras toditas de alegría y que toquen una juga que hoy sí vamos adorar.

Al terminar el diálogo, actores y público aplauden y piden que la banda de músicos y las cantoras interpreten una juga, el aire musical característico de la festividad. La forma más extendida de las jugas consta de un verso, cantado por la voz principal o encoradora y un coro con el que responden las demás cantoras y los asistentes por igual. El siguiente es un fragmento de la juga de adoración Vamos a adorar (grabación de 2008): 


\author{
Yo quisiera que María \\ Vamos a adorar (coro) \\ a la gloria me llevara \\ para ya adorar el Niño \\ que en la cuna no llorara \\ Vamos a adorar (bis) \\ que niñito tan bonito \\ que al portal se apareció \\ y en los brazos de su madre \\ la madrina lo cogió \\ Vamos a adorar (bis)
}

Esta forma es replicada por los instrumentos que acompañan la celebración, lo usual es un conjunto de trompeta, saxofón alto, clarinete, trombón, redoblante, bombardino, tuba y bombo con platillos (Palau Valderrama, P., 2007). Aunque la instrumentación puede variar, en todos los casos apoya una de las actividades centrales de la festividad: bailar frente al pesebre. Esta danza se hace en fila india, con movimientos sinuosos que coordina un líder espontáneo. Después de muchas horas de dramatización, fiesta, aguardiente y comida en los toldos que se levantan cerca del pesebre, algunos de los asistentes se marchan a sus casas. Otros se reúnen a bailar música comercial (salsa, vallenatos, reggaetón) en las casetas aledañas que se montan para la ocasión, mientras las síndicas, capitanas y cantoras bailan y cantan jugas hasta el amanecer.

\section{“Ángel vos te vas pa'l cielo”: bundes, jugas y salves para decir adiós}

$\bigcup \begin{aligned} & \mathrm{N} \\ & \mathrm{t}\end{aligned}$

N SEGUNDO CONTEXTO DE GRAN IMPORTANCIA PARA LA PRÁCTICA MUSICAL tradicional en Villa Rica son los velorios de niños y adultos.

En ambos casos hay acompañamiento vocal a cargo de una o más cantoras (en el caso de los niños se incluye una tambora). Al igual que en muchas comunidades ribereñas y costeras de la zona del litoral pacífico colombiano, la tragedia por la muerte de un menor de siete años es mitigada con una celebración, pues se ve al difunto como un "angelito", sin pecado alguno, que desde el cielo velará por los parientes que quedan en la tierra, particularmente por sus padres y sus padrinos. Esta relación entre muerte y regocijo, contradictoria para otras sociedades, se aprecia en el 
siguiente fragmento de un bunde, que es como se denomina el género musical que se interpreta durante la primera noche del fallecimiento (grabación de 2008):

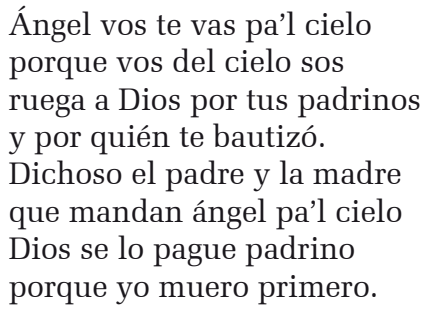

El término bunde tiene una doble connotación: es al mismo tiempo el nombre del velorio de un pequeño (un evento social de enorme significado y convocatoria dentro de la comunidad) y el nombre del género musical propio del velorio. Por claridad, dentro del texto hablaremos de bundes para referirnos a la primera acepción y de cantos de bunde para la segunda, aunque en Villa Rica se utiliza el mismo término para ambos casos.

Al bunde asisten familiares, vecinos, amigos y gente cercana a la familia sin distingo de edad (es habitual encontrar madres con sus niños que participan en el ritual de despedida). Acaecida la muerte del menor, padres y padrinos disponen de su casa para hacer la velación; es necesario un recinto amplio, generalmente la sala o uno de los espaciosos patios que son habituales en Villa Rica, donde puedan ubicarse el féretro, asientos o bancas de madera y donde, además, los asistentes puedan bailar. También debe contarse con un generoso acopio de café negro, comida y aguardiente que acompañe a los asistentes hasta el otro día.

Los bundes es cuando se muere un niño. Entonces se llama a los testigos, se les avisa, se busca una mesita, se buscan dos velas, dos botellas con las velas, flores y se pone una camita encima del ataúd. Luego llega la gente y se consigue la tambora, se consigue aguardiente y se canta Para bien al niño. De allí pa'llá ya se sigue hasta la madrugada, hasta el otro día con la gente que aguante. (LD, mujer, 72 años.)

Los bundes tienen un espíritu mucho más íntimo que las Adoraciones y en ellos se aprecia la estrecha relación entre la música y diferentes concepciones sociales. Un primer indicio de esto es la instrumentación empleada; a diferencia de las Adoraciones, cuando se va a "bundear" un niño no se precisa de 
9. En ocasiones, puede haber también una guitarra o una armónica. Sin embargo, el "color" del acompañamiento musical se mantiene siempre dentro de la solemnidad que imprime la tambora y la intensidad de la música que permite el protagonismo de las cantoras. ningún otro instrumento distinto a la tambora ${ }^{9}$, que con su sonido característico, hondo y opaco, es el principal símbolo del espíritu de la reunión. De hecho, una vez el recinto ha sido adecuado y cae

la tarde, un toque de tambora en la puerta de la casa es la señal inequívoca de que va a empezar el velorio.

Un segundo indicio de la relación entre los cantos de bunde y el imaginario popular se observa en los contenidos de las letras que entonan las cantoras. Con igual importancia que la tambora, la encoradora y su coro responsorial imprimen el tono de cada momento de la velación. Así, al principio hay nostálgicos cantos de despedida, marcados por la tambora en un cadencioso tiempo similar al del vals, ventana a diferentes nociones sobre crianza de los niños y relaciones sociales como el padrinazgo. En ocasiones hay improvisaciones que incluyen el nombre de la madre y que hacen alusión a las diferentes razones para la partida del angelito, en un complejo texto que habla, en últimas, de ideas comunes sobre salud infantil. A continuación presentamos dos versiones del canto de bunde Comadre Jacinta. El primero es tomado de la grabación de Portes de Roux, H. (I986b) y el segundo de la hecha en el presente estudio. Obsérvense las adecuaciones del nombre de la madre y las causas del fallecimiento:

¿El hijo e' Jacinta por qué se murió? ¿El hijo e' \acinta por qué se murió? Fue leche cortada lo que lo mató Lo que lo mató, lo que lo mató.
¿El hijo de Daisy por qué se murió? ¿El hijo de Daisy por qué se murió? Fue porque le dieron mucho arroz Mucho arroz, mucho arroz.

Más entrada la noche, el repertorio varía para incluir jugas de bunde, cantos mucho más alegres y acompañados por la tambora en un tiempo sincopado similar al de las jugas de Adoración. La alusión en estas jugas a la muerte del niño no es tan directa como ocurre con los cantos de bunde y narran situaciones típicas de la vida rural de la región, que contienen más personajes y nombres de parajes. Son música para bailar y también tienen una estructura de pregunta y respuesta. Trascribimos a continuación un fragmento de la juga de bunde $\tilde{N} a$ Manuela (grabación de 2008):

Na Manuela menee bien y no se vaya jumar 
que si la gente la ve

qué dirán y qué dirán.

En el monte todo palo

tiene su comparación

unos sirven para santo

y otros para hacer carbón.

Dale duro a la tambora

que se acabe de romper

que en el monte hay mucho cuero

para poderla componer.

El bunde concluye a la mañana siguiente, cuando los asistentes se retiran y los deudos se dedican a organizar los preparativos para el entierro del angelito.

Dentro del mismo culto a la muerte están los velorios de las personas adultas. Estos son hechos sociales que tienen asimismo acompañamiento musical y lírico pero sin el regocijo observado en los bundes ni con tambora. Al igual que en los bundes, los deudos preparan una habitación de la casa que recibirá a los visitantes y un altar organizado con diferentes elementos en torno al féretro. Durante la primera noche, las intervenciones de las cantoras son de dos órdenes: rezos recitados y salves cantadas. Una vez llegan los asistentes al velorio y antes de rezar el rosario, la encoradora entona una salve (grabación de 2008):

\footnotetext{
Dime, el niño está enojado

lleno de melancolía

porque las cristinas no reza

el rosario de María.

Cinco son los pater nostri...

del santísimo rosario

cinco son los que se rezan

para ir al cielo a gozarlo.
}

El velorio continúa hasta el amanecer, con rondas periódicas de aguardiente en pequeñas copas con café. Sin las bebidas y sin los salves, el ritual se repite durante las ocho noches siguientes hasta completar el novenario. Tanto los bundes como los velorios de adultos siguen vigentes en Villa Rica. 


\title{
"No me escribas": canciones para los amigos y para el trabajo
}

\begin{abstract}
DEMÁS DE LOS CANTOS EN TORNO A LA NATIVIDAD Y A LOS VELORIOS, LA tradición de práctica musical vocal en Villa Rica tuvo otro importante espacio de consolidación en numerosos espacios de reunión de amigos con fines de socialización o de trabajo, entre los que sobresalen las quemas, los bailes de socio y las jornadas de cosecha en las fincas familiares. En los tres casos, hombres y mujeres cantaban con músicos contratados o miembros de la comunidad, ante la ausencia de radios y la escasez de tocadiscos, aparatos suntuosos reservados para los locales de diversión en los municipios cercanos. Las características de estos espacios y la música involucrada sólo pudieron reconstruirse a partir de testimonios, porque lastimosamente han desaparecido.
\end{abstract}

Las quemas eran homenajes musicales que un amigo (hombre o mujer) le hacía a otro a manera de desagravio por alguna ofensa menor. Consistía en llegar de sorpresa y pasada la medianoche a la casa del agraviado, llevando músicos, bebida, pólvora y amigos para saldar la afrenta en medio del baile y el jolgorio. Las descripciones hacen pensar en las serenatas contemporáneas, empero hay marcadas diferencias. Por una parte, las quemas no tenían ninguna connotación romántica ("las serenatas son para enamorados", nos corrigió una de las entrevistadas cuando hicimos la comparación), segundo, eran una pequeña fiesta repentina que duraba hasta la mañana siguiente y tercero, implicaba un ritual de simulación entre el oferente y el agraviado. Cuando alguien decidía hacerle una quema a un amigo, dejaba entrever su intención durante visitas anteriores o con mensajes a través de terceros:

Digamos que un día yo paso por su casa y usted está medio sentido conmigo, me saluda frío y no me hace la charla. Entonces yo digo: "Le voy a hacer una quema a mi compadre". Entonces yo vuelvo a pasar en la semana, lo vuelvo a saludar y miro la sala o sobre todo le miro el solar desde afuerita y le digo que tan amplia, que bueno para hacer alguna cosa o le mando a decir con la hija que se alisten, que de pronto les llega una sorpresa. Y entonces uno ya sabía "mi comadre me va a hacer una quema”. En mi casa una vez le hicieron una a mi mamita (abuela) Magdalena; ella se enteró y nos pasamos dos días barriendo ese solar y lavando todo por si acaso. Y en la madrugada, fijo, sonaron los cohetes y mi mamita bailó hasta decir no más. (AO, mujer, 89 años.) 
Estas manifestaciones implicaban una relación de reciprocidad, de forma tal que si una persona "le hacía una quema" a otra, con el tiempo el homenajeado devolvía las atenciones de la misma manera.

Otro espacio de igual importancia para socialización eran los bailes de socio o fiestas que se realizaban los sábados para amanecer el domingo o de domingo a lunes, en los espaciosos patios de las casas de Villa Rica y de muchas de sus veredas como Primavera, Mingo o El Palito. También conocidos como recreaciones, los bailes de socio no tenían la connotación de desagravio aunque sí compartían la noción de reciprocidad: el anfitrión prestaba el patio y todos los asistentes ponían una cuota para pagar la bebida, la comida y la música en vivo. La siguiente es una descripción hecha por una cantora originaria de la vereda Primavera y radicada en Villa Rica desde los años 80:

— ¿Y una fiesta de socio era para gente de qué edad?

- Gente joven. Digamos usted tenía una novia pero no se podía entrevistar con ella, ni tocarla porque era prohibido. Entonces usted quería amacisarse porque se usaba mucho el bolero, entonces allí usted si llegaba y amacisaba a su novia y bueno, era una sociedad que había. Porque en otras partes a la fija que había muchos cuidanderos, los viejos. Yo lo invitaba usted, y entonces usted me decía pasitico “invíteme la novia, vaya allá..., mándele razón”. Uno iba de boca al papá y le decía, le daban permiso. El novio le daba la contribución a uno para que la llevara. Era una cosa que usted llegaba allá tranquilo, y cuando salían a bailar cada uno sacaba su pareja y todo mundo podía bailarse su bolero. (VP, mujer, 70 años.)

Los bailes de socio eran un espacio de interacción en torno a la música en vivo, que ofrecía una valiosa posibilidad a los jóvenes en edad de tener novio(a), de encontrarse con sus congéneres en condiciones aceptables para los familiares mayores.

Un tercer espacio de interacción de amigos donde se daban prácticas musicales eran las jornadas de cosecha en fincas familiares. A diferencia de las quemas y los bailes de socio, estas reuniones no tenían como fin último socializar en torno a la música, pero sí incluían cantos liderados por las mujeres y acompañados por niños que eran llevados a la jornada.

- Yo ya desde los ocho años o antes trabajaba en la finca de mi mamita. Y ya señorita íbamos con otras niñas a coger cacao, que era 
lo que se daba por acá. Eso era cosa de mujeres porque los hombres han sido malos para coger cacao, se enredan y no lo hacen bien. En eso a uno se le iba el día entero de finca en finca.

— Usted me decía que allí también cantaban...

— iUuuu! Cantábamos. Eso cantábamos cosas que uno se sabía y hacía más alegre el ratico. Era música para el amor. Entonces si alguna tenía un enamorado o un pretendiente, pues nosotras cantábamos algo para que ella se aliviara. Esas canciones uno las escuchaba en los bailes o a veces le traían cancioneros del Puerto [Puerto Tejada] o de Cali y uno les ponía la música. Eran unos cancioneros muy bonitos, con imágenes que a uno lo ponían a soñar. Imagínese, uno bien jovencita y bien tragada. A veces juntábamos centavos y nos comprábamos una botella de aguardiente y la dejábamos por ahí en un rastrojito; entonces era cantar, tomar cocha (aguardiente) y coger cacao (risas) (AO, mujer, 89 años.)

En las quemas, los bailes de socio y las jornadas de laboreo se combinaban distintos géneros musicales: jugas de bunde, torbellinos y canciones. Este último, llamado así por las cantoras, plantea un caso interesante ya que en realidad son adaptaciones de música popular comercial (tangos, boleros y guarachas) a las que se tenía acceso a través de cancioneros o de oídas en un viaje que se hiciera a centros urbanos como Puerto Tejada o Cali.

\title{
"NO VENGO A PEDIRTE NADA": \\ RECURSOS PARA REALIZAR PRÁCTICAS MUSICALES EN VILLA RiCA
}

\begin{abstract}
A PRÁCTICA MUSICAL EN CADA UNO DE LOS TRES CONTEXTOS DESCRITOS impone una serie de exigencias tanto de recursos físicos como de trabajo humano. Como veremos, tradicionalmente ambos se han conseguido a través de la participación solidaria de diferentes miembros de la comunidad.
\end{abstract}

\section{Música para Adoraciones: recursos físicos y humanos}

\footnotetext{
N TÉRMINOS DE RECURSOS FÍSICOS, LA REALIZACIÓN DE LAS ADORACIONES

- implica reunir materiales para la elaboración de los disfraces - de los miembros que participan en el montaje teatral (madrinas,
} 
padrinos, gitanos, reyes, príncipes, ángeles, indígenas, santos, reyes magos y soldados), un espacio para realizar ensayos durante los dos meses previos a la noche de Adoración y alimentos para refrigerios durante los ensayos. En lo que respecta a la jornada de celebración, es preciso tener lugar para hospedar a los visitantes de otras poblaciones y a los músicos que se contratan, comida y licor para los participantes, un montaje de pólvora (conocido como "castillo) y dinero en efectivo para cubrir los honorarios de los músicos.

Las necesidades de trabajo humano surgen en cada una de estas etapas. Durante la etapa de preparación de la Adoración son indispensables personas con destrezas manuales para hacer los disfraces y los altares. Están también aquellos con habilidades musicales y de actuación que preparan las coreografías y orientan a los niños en la declamación de las loas, así como los percusionistas que acompañan los ensayos (un tamborero). Durante la jornada de Adoración son imprescindibles cocineras que preparen los fiambres para los visitantes y hombres que levanten las barracas (construcciones ligeras de madera y hoja de palma) en torno al lugar donde se realizará la celebración. Finalmente están los que participan en el montaje artístico: actores, músicos, declamadores y bailarines que forman parte de la procesión y, luego, del baile de Adoración que se extiende hasta la mañana siguiente en frente del pesebre.

La investigación mostró que las exigencias de trabajo humano identificadas arriba han sido suplidas a través de la participación comunitaria voluntaria en todas las etapas, con excepción del personal encargado de elaborar y quemar el castillo de pólvora y de la banda de músicos de viento que acompañan la jornada de Adoración, quienes reciben honorarios en efectivo. Sin embargo, como se describirá más adelante, el dinero para esto se consigue a través de trabajo voluntario.

Hasta hace unas dos décadas los recursos en efectivo se solventaban a través de donaciones en especie y en metálico, todo en el marco de lo que puede considerarse como la más importante actividad, en términos de gestión para realizar Adoraciones: la colecta. Esta consistía en la peregrinación de un grupo de voluntarios que todos los domingos recorría los caminos polvorientos de las veredas del municipio y visitaba las fincas familiares para pedir colaboración. El nutrido grupo, 
"No vengo a pedirte nada": la música en Villa Rica, Cauca...

integrado por cantoras, músicos de percusión y niños, llegaba a la puerta de la casa y entonaba jugas de adoración con letras explícitas respecto a los donativos, como evocan dos cantoras participantes en el estudio:

CP: Uno arrancaba la colecta por ahí dos meses antes de la Adoración. Los domingos, desde las ocho porque había mucha finca para caminar. Nosotros llegábamos a una casa y había personas que les encantaba la música y nos hacían entrar, ellos daban la limosna y si tenían hijas y jóvenes arrancaban a acompañar con uno. Eso era una unión muy bella.

VP: Se le olvida lo de las jugas, tenía que cantar una o dos jugas. Por eso teníamos que andar con la tambora porque en cada casa había que cantar una juga. Como uno decir, Niño bonito, Niño bonito. Entonces allí uno agarra a bailar.

— ¿Cuál es una de esas jugas que uno cantaba para pedir la colecta? VP: Decíamos: Vámonos don Juan, cuando ya íbamos a salir y arrancábamos a cantar (todas a capella):

Los reyes del Oriente se salieron a ofrecer, los reyes del Oriente se salieron a ofrecer sus cetros y sus coronas como un soberano Rey.

No vengo a pedirte nada y tampoco a que le den no vengo a pedirte nada y tampoco a que le den vengo a pedirte licencia para entrar a Belén vengo a pedirte licencia para entrar a Belén Adiós mi Niñito Dios...

La colecta empezaba al menos dos meses antes de la noche de Adoración y recibía todo tipo de aportes. Si la donación era en especie (huevos, legumbres, animales de corral, ropa), se vendía; si era en efectivo, pasaba a engrosar la bolsa con la que se cubrirían los gastos. Tanto la organización de la colecta como la administración de los recursos resultantes suponían una habilidad particular para garantizar la viabilidad de las fiestas.

VP: La gente nos colaboraba... los vestidos de la madrina y todo eso...

CP: Los ponían las madres, ellas nos vestían. Para la fiesta como era pólvora se quemaba hasta castillo, porque eso es viejísimo la quemada del castillo para las Adoraciones. Entonces cada ocho días, los domingos salían para hacer esa recolecta en los caseríos, las veredas. Entonces se salía uno, lo llevaban los mayores a... todo mundo. Eso eran viejos, muchachos, a orar con el Niño de casa en casa. En 
ese entonces la colaboración era de café, cacao y plátano. Gallina, huevos, eso era lo que se recolecta. Entonces ese artículo se vendía. - ¿La colaboración era para vender?

VP: Claro, claro. Uno llega y en cada casa le dan de a dos centavos, tres centavos, así. Esa plata la cogía la tesorera, por decir, mi comadre C, la capitana, y la guardaba para cuando ya la terminación de las Adoraciones, esa plata servía para ayudar a pagar los músicos y como no teníamos quién nos daba...

CP: Por eso, el cacao y el café lo daban. Entonces si eso lo daban verde había que acabarlo de secar, quien más se interesaba en eso era don Trino Viveros, que era el capitán. Si llevaba huevos, eso se vendía entre los mismos. Si usted necesitaba huevos... de lo que se recolectó hay huevos, véndame. Entonces esa plata se iba recogiendo.

La práctica de la colecta ha decaído en años recientes. Según los testimonios, en el sector de Villa Rica hace casi cinco años que se realizó la última y se hizo en las calles aledañas al casco urbano.

\section{Música para los amigos: recursos físicos y humanos}

AS PRINCIPALES EXIGENCIAS DE RECURSOS FÍSICOS, EN EL CASO DE LOS desaparecidos bailes de socio, eran garantizar la disponibilidad -de un patio o un solar que alojara la fiesta y reunir los fondos en efectivo para comprar el licor y cubrir los honorarios de los músicos participantes. Lo primero se lograba por la voluntad de alguno de los asistentes y se establecía una especie de cadena de corresponsabilidad, de forma tal que una casa era la sede del baile y las otras del caserío o la vereda quedaban disponibles para futuras ocasiones. Lo segundo, el efectivo, se conseguía a través de aportes individuales previos realizados por los "socios" (de allí el nombre de la práctica):

IP: El baile de socio era una contribución que se les ponía a los invitados. Entonces uno daba una tarjetica: el baile de socio va a ser aquí donde C. Entonces usted le daba la plata al que lo estaba organizando, lo de la bebida y la comida que a veces había. Y lo de los músicos, claro, que también cobraban. Entonces usted llegaba con su novia bien tranquilo al baile de socio y ya estaba todo pago.

VP: Cada uno con su pareja.

IP: Y allí la banda de música a tocar hasta el otro día pa’bailar. 
Las exigencias de trabajo humano eran la preparación de la sede de la fiesta, la compra del licor y el aseo posterior. Todo estaba a cargo de los voluntarios del grupo organizador. Algo similar ocurría en el caso de las también desaparecidas quemas. Las demandas de recursos físicos eran, básicamente, las relacionadas con conseguir el dinero para comprar la pólvora (a diferencia de los imponentes castillos de las Adoraciones, aquí se trataba de cohetes) y el aguardiente, y con ofrecer comida y espacio para realizar la celebración. Los gastos de licor y "cohetería" eran asumidos por el oferente, mientras que lo restante se solventaba con los recursos disponibles en casa del homenajeado. En el caso específico de la comida se daba una práctica que aún subsiste en Villa Rica: la preparación de "una seca". Esta consiste en cocinar, de manera improvisada, grandes cantidades de arroz combinado con lo que haya disponible en la alacena al momento de la visita: zanahoria, tomate, maíz cocido y, en años recientes, atún o sardinas enlatadas. Todo se mezcla en una gran olla y se pone a secar en un fogón que queda a la vista de los asistentes (esto le da el nombre al plato). Se acompaña de "aguafresca", una bebida fría a base de limón o naranjas. No debe olvidarse que, como ya se dijo, las quemas suponían una relación de reciprocidad y el homenajeado anticipaba devolver las atenciones en un futuro próximo. En cuanto al trabajo físico durante las quemas, este se limitaba a la organización previa (conseguir pólvora, licor y músicos), a la preparación de alimentos y a la atención de los comensales. Todo se hacía de forma voluntaria.

Las jornadas de recolección de cacao y otros alimentos (como maíz), eran una instancia de trabajo colectivo hacia un fin común, por lo tanto, los recursos humanos estaban garantizados debido a la dinámica del contexto. En cuanto a las obligaciones económicas, las mujeres participantes en la recolección juntaban dinero para comprar una botella de aguardiente que acompañaba las faenas.

Música para velorios:

recursos físicos y humanos

N ESTE CASO LAS EXIGENCIAS SON MUCHO MENORES QUE LAS DE LAS FIES-
tas de Adoración, las quemas y los bailes de socio. En cuanto
a recursos físicos, la realización de un bunde o de un velorio 
de adulto implica disponer de licor (por lo general Aguardiente Caucano), café y, en ocasiones, comida para los visitantes. Si se trata de un bunde, en la mayoría de los casos son los padrinos del menor fallecido quienes asumen estos gastos, así como los funerarios. Si es de un adulto, la familia asume estas responsabilidades. En lo relacionado con el trabajo humano, los bundes exigen la participación de cantoras y tamboreros y los velorios de adulto la participación de una mujer que elabore el altar funerario y presida la entonación de las salves y los rezos. En ambas circunstancias también se observa la dinámica de trabajo voluntario descrita para las otras prácticas musicales, pues cantoras, rezadoras y músicos acompañantes (en el caso de los bundes) asisten a las ceremonias sin ningún tipo de expectativa de retribución económica.

\section{Análisis}

\section{Solidaridad y valores colectivos}

 N LOS CONTEXTOS DESCRITOS, LA PRÁCTICA MUSICAL TRADICIONAL COrrespondiente es una instancia para la puesta en común y reafirmación de distintos valores colectivos de gran significado para la comunidad, que se hace posible gracias a un profundo sentido de solidaridad. Esta se entiende en el sentido propuesto por E. Durkheim (1984) de adhesión y compromiso a una causa de otros, motivada por una elevada conciencia colectiva y la adhesión a valores promulgados por el grupo (la idea de solidaridad mecánica, expuesta en su texto clásico La División del Trabajo Social). Cabe aclarar, antes de proseguir, que no entendemos las prácticas musicales tradicionales como instancias sociales para "aprender a ser solidario"; más bien sirven para reafirmar valores y creencias colectivas a través de una práctica musical que implica la participación solidaria de los miembros del grupo. ${ }^{10}$ Desde este punto de vista, son escenarios que contribuyen a ese proceso de formación en valores sociales y de reafirmación de estos mismos, con los que en el futuro el individuo se identifica

IO. De hecho, el concepto de solidaridad mecánica que plantea Durkheim está fundado en la existencia de valores colectivos muy fuertes y de una estructura social que favorece la integración del individuo a la sociedad a partir del establecimiento de similitudes (Müller, H. P., I994, pp. 8I-82). 
"No vengo a pedirte nada": la música en Villa Rica, Cauca...

en distintos grados y, por supuesto, la solidaridad termina siendo uno de los valores reafirmados.

La participación solidaria se manifiesta de distintas formas. Un primer ejemplo de esto se aprecia en la manera como se atienden las exigencias de recursos físicos y de trabajo humano que impone cada contexto social. En una práctica que se mantiene hasta la actualidad, estas demandas han sido resueltas a través de trabajo voluntario, donaciones en especie y en efectivo y, hasta hace poco tiempo, participación en colectas para generar ingresos adicionales.

El segundo ejemplo está más relacionado con los valores que se reafirman a través de la práctica musical, todos con una clara connotación de colectividad. Las Adoraciones consolidan la devoción religiosa católica y establecen una serie de roles para incluir a todos los miembros de la comunidad y aunque existen claras jerarquías para esa participación, son incluyentes y permiten una alternancia en el liderazgo de las actividades que se observa en el hecho de que una persona puede pasar de ser miembro anónimo de la procesión a ser protagonista como líder del baile de la juga frente al pesebre. En la misma línea, los bundes y los velorios de adulto evidencian la convicción colectiva de que los deudos no deben dejarse solos y de que el círculo social cercano tiene que acompañarlos en una plegaria comunal, que sirve de bálsamo para la honda pena y de estructura de soporte para la toma de decisiones ante la pérdida. Por último, en los desaparecidos contextos de quemas, bailes de socio y jornadas de cosecha se materializaba la idea colectiva de mantener espacios socialmente controlados para la interrelación de las nuevas generaciones y para la discusión de diferencias, tribulaciones y expectativas de los miembros de la comunidad.

Un tercer ejemplo de manifestación de este profundo sentido solidario se relaciona con los aspectos formales de la práctica musical. La gran mayoría de los géneros tradicionales identificados en Villa Rica tienen una estructura responsorial y requieren distintos niveles de acompañamiento musical, características que precisan la participación de varios miembros de la comunidad. La ejecución también distingue elementos en este sentido. En el caso de Villa Rica la división tajante entre intérpretes y audiencias (los que saben hacer música y los que la escuchan) se desdibuja y se observa una enorme fluidez bajo la idea generalizada de que 
todos los miembros de la comunidad pueden intervenir en el hecho musical. Una significativa muestra de esto se dio en una de las primeras jornadas de grabación para el presente estudio. La invitación se extendió a diez cantoras y un tamborero, pero cerca de veinticinco personas más acudieron a la cita, incluyendo niños y hombres mayores. Cuando preguntamos por su presencia una de las cantoras respondió con total naturalidad: "Es que ellos también se saben los cantos. Y además bailan”. En otras palabras, la música tradicional de la región no es para solistas sino para el grupo.

\section{Dinámicas colaterales y actores internos}

OS CONTEXTOS DESCRITOS SON INSTANCIAS SOCIALES QUE DAN ORIGEN A una especie de red (para retomar la idea de C. Geertz expuesta -al principio) donde se entretejen valores colectivos y prácticas musicales. Esto nos lleva a afirmar que la apropiación de la música tradicional en Villa Rica por parte de los miembros de la comunidad, se ha dado como instancia de transformación o afirmación cultural a través de una dinámica colateral. Es decir, no se derivan ni de una iniciativa pedagógica para aprender a cantar o a tocar tambora, ni de una ideológica que se proponga forjar o reafirmar los valores comentados. Son más bien procesos que resultan de la participación y vinculación de las personas a las actividades sociales donde está presente la música, pero sin que esta sea el epicentro.

Este planteamiento nos permite apreciar la relevancia que tiene la vida en comunidad para el aprendizaje musical, pues los niños son introducidos a la práctica musical a partir de hacer música en contexto: se aprende la tambora tocando y a responder una juga cantando, al tiempo que se baila, se hacen chistes y se come un sancocho. ${ }^{11}$ Este es un argumento muy importante a favor de la orientación conceptual expuesta aquí de que las prácticas musicales son una circunstancia social, un espacio donde se hace sociedad y no un mero reflejo de la sociedad. ${ }^{12}$

II. Esto contrasta con dinámicas habituales de pedagogía musical donde los niños van por una hora a aprender a tocar o a cantar, algo que G. Booth y T. Kuhn (I990) asocian con otros tipos de música.

I2. Una lectura similar se encuentra en Feld, S. y Fox. A., 1994, p. 38; y Horner, B., I998, p. I60. 
"No vengo a pedirte nada": la música en Villa Rica, Cauca...

\title{
Conclusiones
}

\begin{abstract}
LO LARGO DEL PRESENTE TEXTO HE EXPLORADO DIFERENTES ELEMENTOS que forman parte del panorama musical del municipio de Villa Rica, al sur del valle geográfico del río Cauca. Al prinicipio se identificaron y describieron tres contextos sociales y sus correspondientes prácticas musicales tradicionales: fiestas religiosas (Adoraciones y Fiesta de Reyes), velorios (bundes y salves) y encuentros de socialización (quemas, bailes de socio y cantos de laboreo). Hecho esto, vimos cómo las exigencias de recursos físicos y humanos que imponen cada una de estas prácticas musicales son atendidas a través de una lógica de trabajo solidario, vigente hasta años recientes.
\end{abstract}

La compleja red que se teje entre elementos musicales, dancísticos y líricos dentro de estos contextos es una importante instancia para la comunicación, transformación y reafirmación de parámetros sociales en la comunidad. Ahora bien, dado que las prácticas musicales ocurren en estrecha articulación con otros hechos sociales es posible afirmar que la mayoría de estos procesos han ocurrido y ocurren en la actualidad de acuerdo con una dinámica colateral, donde personas provenientes de la comunidad (agentes internos), en su mayoría mujeres mayores, juegan un papel preponderante.

De otro lado, el estudio reveló que algunas de las prácticas musicales descritas han desaparecido del municipio, como es el caso de la Fiesta de Reyes, las quemas, los bailes de socio y los cantos de laboreo. Las razones para este desvanecimiento y, en general, las transformaciones en el panorama musical de la región con respecto al que describen estudios hechos en los años 8o serán abordadas en otro momento. Sin embargo, el trabajo estrecho con músicos y cantoras de Villa Rica nos brinda elementos para ser optimistas frente a la permanencia de las prácticas musicales tradicionales, a pesar de los innumerables retos y dificultades que enfrenta la comunidad en términos económicos y sociales. Villa Rica tiene una larga historia de trabajo colectivo y son muchos los casos donde se ha superado la escasez de recursos físicos o los cambios traumáticos, para lograr un objetivo común; prueba de ello son las colectas para realizar Adoraciones y la misma ubicación actual del municipio, cuyo caserío original fue trasladado por sus habitantes luego de una creciente del río Cauca en 
el lugar de fundación. Consideramos que si la academia local y nacional, los entes oficiales y la empresa privada asentada en el sector trabajan de forma articulada con los diferentes sectores de la comunidad que mantienen hoy en día el interés por su tradición musical, hay buenas posibilidades de evitar que en unos pocos años los cantos sean sólo un recuerdo nostálgico que silbe en la memoria de los cañaduzales que rodean Villa Rica, el norte del Cauca y el sur del Valle.

\section{BibliogRAFíA}

Angulo, M. E. (2005). Creando y recreando la voz de los abuelos. Conferencia en Encuentro Internacional de Historia Oral "Oralidad y Archivos de la Memoria”. Mayo 5, 6 y 7 de 2005.

ApriLe, J. (1994). Los pueblos de negros caucanos y la fundación de Puerto Tejada. Cali: Gobernación del Valle del Cauca.

AristiZÁbal, M. (2005). Las fiestas de “adoración al niño” en QuinamayóColombia. ¿Evidencia de resistencia cultural o estrategia política para ganar reconocimiento? Conferencia en Coloquio IDYMOV-“Construir y vivir la diferencia. Los actores de la multiculturalidad en México y Colombia”. CIESAS-IRD-ICANH-CEMCA-CREDAL, Xalapa, Ver., México. Noviembre 8-II de 2005.

Arocha, J. (1995). Unidades de producción nortecaucanas (Colombia): modernización y funcionamiento. América Negra, 9, I85-205.

Atencio, J. y CAstellanos, I. (I982). Fiestas de negros en el norte del Cauca: Las adoraciones del Niño Dios. Cali: Universidad del Valle.

Bermúdez, A. (1997). Cimarronismo, costumbre y cultura en Puerto Tejada. En F. Zuluaga y A. Valencia (editor académico), Puerto Tejada 100 años (pp. 35-5I). Puerto Tejada. Alcaldía Municipal de Puerto Tejada.

Blau, J. R. (1988). Music as Social Circumstance. Social Forces, 66 (4), 883-902.

Bоотн, G. D. y Kunn, T. L. (1990). Economic and transmission factors as essential elements in the definition of folk, art, and pop music. The Musical Quarterly, 74 (3), 4II-438.

CAICEDO, M. (2003). Descomposición de la economía campesina y condición de la mujer en el norte del Cauca. Anuario de investigaciones, 3, 66-83. 
"No vengo a pedirte nada": la música en Villa Rica, Cauca...

Colmenares, G. (I983). Cali: Terratenientes, mineros y comerciantes (siglo XVIII). Bogotá: Banco Popular.

Conklin, B. A. (1997). Body Paint, Feathers, and VCRs: Aesthetics and Authenticity in Amazonian Activism. American Ethnologist, 24 (4), 7II-737.

De Roux, G. y Yunda, A. C. (200I). Procesos, políticas y coyunturas regionales y sus efectos sobre el campesinado. Anuario de investigaciones, I.

Díaz de Zuluaga, Z. (I983). Guerra y economía en las haciendas: Popayán 1780-1830. Bogotá: Banco Popular.

Durkheim, E. (I984). The Division of Labor in Society, 2 ed. New York: The Free Press.

FELD, S. y Fox, A. (1994). Music and Language. Annual Review of Anthropology, 23, 25-53.

GeErtz, C. (2000). La interpretación de las culturas. Barcelona: Gedisa.

GINSBURG, F. (I99I). Indigenous Media: Faustian Contract or Global Village? Cultural Anthropology, 6, 92-II2.

Hesmondhalgh, D. y PRATt, A. C. (2005). Cultural Industries and Cultural Policy. International Journal of Cultural Policy, II (I): 2:I3.

Horner, B. (I998). On the Study of Music as Material Social Practice. The Journal of Musicology, I6 (2), I59-I99.

JARAmillo Uribe, J. (200I). Ensayos de historia social. Bogotá: Ceso, Uniandes, Banco de la República, Instituto Colombiano de Antropología e Historia, ICANH, Colciencias, Alfaomega.

Kondo, D.K. (I997). About Face: Performing Race in Fashion and Theater. New York: Routledge.

Mahon, M. (2000). The Visible Evidence of Cultural Producers. Annual Review of Anthropology, 29, 467-492.

Mina, M. (I975). Esclavitud y libertad en el valle del río Cauca. Bogotá: Ediciones La Rosca.

MiÑAna, C. 2008. Música y fiesta en la construcción del territorio nasa (Colombia). Revista Colombiana de Antropología. Vol. 44 (I), I23-I55.

MülleR, H. P. (I994). Social Differentiation and Organic Solidarity: The "Division of Labor" Revisited. Sociological Forum, 9 (I), 73-86.

PAlau Valderrama, P. (2007). Bombarra, tuba y helicón: música tradicional de las adoraciones del niño Dios en el norte del Cauca y sur del Valle. Tesis Maestría en Música con énfasis en Musicología, Facultad de Artes Integradas, Universidad del Valle. 
PitTs, W. (I99I). Like a Tree Planted by the Water: The Musical Cycle in the African-American Baptist Ritual. The Journal of American Folklore, IO4 (4I3), 3I8-340.

Portes De Roux, H. (I986a). Las adoraciones nortecaucanas del Niño Dios: Un estudio etnomusicológico. (Inédito.)

. (1986b). Música religiosa de negros nortecaucanos en las voces de las cantoras de Mingo. LP producido con apoyo de la Universidad del Valle y la Fundación para la Promoción de la Investigación y la Tecnología, Banco de la República.

RAsmussen, L. (1995). From Source to Commodity: Newly-Composed Folk Music of Yugoslavia. Popular Music, I4 (2), 24I-256.

Sevilla, M. (2008). La música del país vallenato: Acuerdos y divergencias en torno a los símbolos musicales de identidad. En J. M. Pereira González, M. Villadiego Prins, L. I.

Sierra GutiÉrRez (Eds). Industrias culturales, músicas e identidades. Una mirada a las interdependencias entre medios de comunicación, sociedad, cultura (pp. 247-270). Bogotá: Editorial Pontificia Universidad Javeriana.

- (2006). Indios pero no tanto: Indians but not quite Indians: Indigenous identity among the Yanaconas of Popayan (Colombia). Tesis doctoral, Departamento de Antropología, Universidad de Toronto, Toronto.

Sevilla, M., M. Birebaum Quintero, L. Convers, O. Hernández Salgar, A., et al. (2008). Componente investigativo del Plan Ruta de la Marimba. Pontificia Universidad Javeriana Cali-Ministerio de Cultura. Cali (inédito).

SHELEMAy, K. K. (2008). The Ethnomusicologist, Ethnographic Method, and the Transmission of Tradition. En G. Barz y T. J. Cooley (Eds.) Shadows in the Field: New Perspectives for Fieldwork in Ethnomusicology (pp. I89-204). New York: Oxford University Press.

Urrea, F. y T. Hurtado. (I997). Puerto Tejada: De núcleo urbano de proletariado agroindustrial a ciudad dormitorio. En F. Zuluaga y A. Valencia (Ed.). Puerto Tejada 100 años. Puerto Tejada: Alcaldía Municipal de Puerto Tejada. 